\title{
NOTCH2 negatively regulates metastasis and epithelial-Mesenchymal transition via TRAF6/AKT in nasopharyngeal carcinoma
}

\author{
You Zou' ${ }^{1 \dagger}$, Rui Yang ${ }^{1 \dagger}$, Mao-Ling Huang ${ }^{1}$, Yong-Gang Kong ${ }^{1}$, Jian-Fei Sheng ${ }^{1}$, Ze-Zhang Tao ${ }^{1}$, Ling Gao ${ }^{2}$ and \\ Shi-Ming Chen ${ }^{1 *}$
}

\begin{abstract}
Background: Clinically, distant metastasis after primary treatment remains a key problem in nasopharyngeal carcinoma (NPC). Thus, identification of the underlying mechanisms and development of novel therapeutic strategies are urgently needed. NOTCH has been shown to function as a tumor promotor that enhances angiogenesis, cancer invasion and metastasis in NPC. However, the precise roles of the four individual NOTCH receptors and their mechanisms of action are unclear.
\end{abstract}

Methods: We used Western blot analysis, immunofluorescence, immunohistochemical analysis, phalloidin staining, mouse tumor metastatic dissemination models, gene set enrichment analysis, immunoprecipitation assays and a series of functional assays to determine the potential role of NOTCH2 in regulating NPC metastasis.

Results: NOTCH2 expression in the NPC tissues of patients with cervical lymph node metastasis was lower than that of patients without cervical lymph node metastasis. Correspondingly, NOTCH2 expression was low in metastatic and poorly differentiated NPC cells. NOTCH2 expression correlated negatively with survival time in patients with NPC. Suppression of NOTCH2 expression promoted NPC cell metastasis, whereas NOTCH2 overexpression inhibited this process. Furthermore, NOTCH2 attenuated the TRAF6-AKT signaling axis via an interaction between the NOTCH2 intracellular domain (N2ICD) and TRAF6, which inhibited epithelial-mesenchymal transition (EMT) and eventually suppressed NPC metastasis.

Conclusions: These findings reveal that loss of NOTCH2 activates the TRAF6/AKT axis and promotes metastasis in NPC, suggesting that NOTCH2 may represent a therapeutic target for the treatment of NPC.

Keywords: NOTCH2, Nasopharyngeal carcinoma, Metastasis, EMT, NOTCH2/TRAF6/AKT axis

\section{Background}

Nasopharyngeal carcinoma (NPC) is a poorly understood epithelial malignancy that is relatively common in certain regions of South China, Southeast Asia and North Africa [1-3]. The incidence of NPC ranges from 15 to 50/100,000 per year in South China and Southeast Asia [4]. Epstein-Barr virus (EBV) infection and environmental and genetic factors have been shown to contribute to the development of NPC [5].

\footnotetext{
*Correspondence: shimingchen0468@163.com

${ }^{\dagger}$ You Zou and Rui Yang contributed equally to this work.

'Department of Otolaryngology-Head and Neck Surgery, Renmin Hospital of Wuhan University, 238 Jie-Fang Road, Wuhan 430060, Hubei, People's

Republic of China

Full list of author information is available at the end of the article
}

Radiotherapy and/or combined chemotherapy are the standard treatments for this disease [6]. Unfortunately, current chemoradiotherapy provides limited benefits in many patients. For example, 30 to $40 \%$ of patients suffer distant metastases within 4 years $[7,8]$, which are associated with a very poor prognosis, mainly because the tumor cells develop chemo- and radioresistance [9]. Therefore, a comprehensive understanding of the molecular mechanisms that promote progression and metastasis in NPC may help to design more effective, targeted treatment strategies.

The NOTCH signaling pathway plays a key role in stem and precursor cell maintenance in several tissues, including the gastrointestinal and glandular tissues [10]. 
However, abnormal expression of NOTCH signaling is linked to the development of several cancers [11]. $\mathrm{NOTCH}$ signaling can promote human gastric cancer cell proliferation [12]. In contrast, the activation of $\mathrm{NOTCH}$ signaling inhibits the growth of small cell lung cancer [13]. Therefore, the NOTCH receptors represent attractive therapeutic targets for cancer [14], provided that their roles in specific tumors are fully elucidated.

We previously reported that all four NOTCH receptors are expressed in NPC cells. The NOTCH inhibitor GSI suppressed NOTCH1, NOTCH2 and NOTCH4 protein expression, but not $\mathrm{NOTCH} 3$ expression, and inhibited proliferation by inducing cell cycle arrest and apoptosis in NPC cell lines [15]. However, the individual role of each NOTCH receptor in NPC has not been elucidated. At the same time, participants in clinical trials presented severe vomiting, diarrhea, anemia and other adverse effects indicating poor tolerance after taking drugs that inhibited all NOTCH receptors [16]. Therefore, for the development of effective, safe and reasonable strategies to treat this disease, researchers must thoroughly elucidate the functions of each NOTCH receptor subtype and develop specific targeted drugs on this basis.

AKT may be a primary regulator of tumor cell activity during multiple stages of tumor metastasis [17]. AKT and AKT-regulated pathways are potential therapeutic targets for early metastatic disease. Shin et al. found that the activation of AKT can promote prostate cancer metastasis [18].

TRAF6 belongs to the TRAF family and has been reported to promote the invasion and metastasis of many

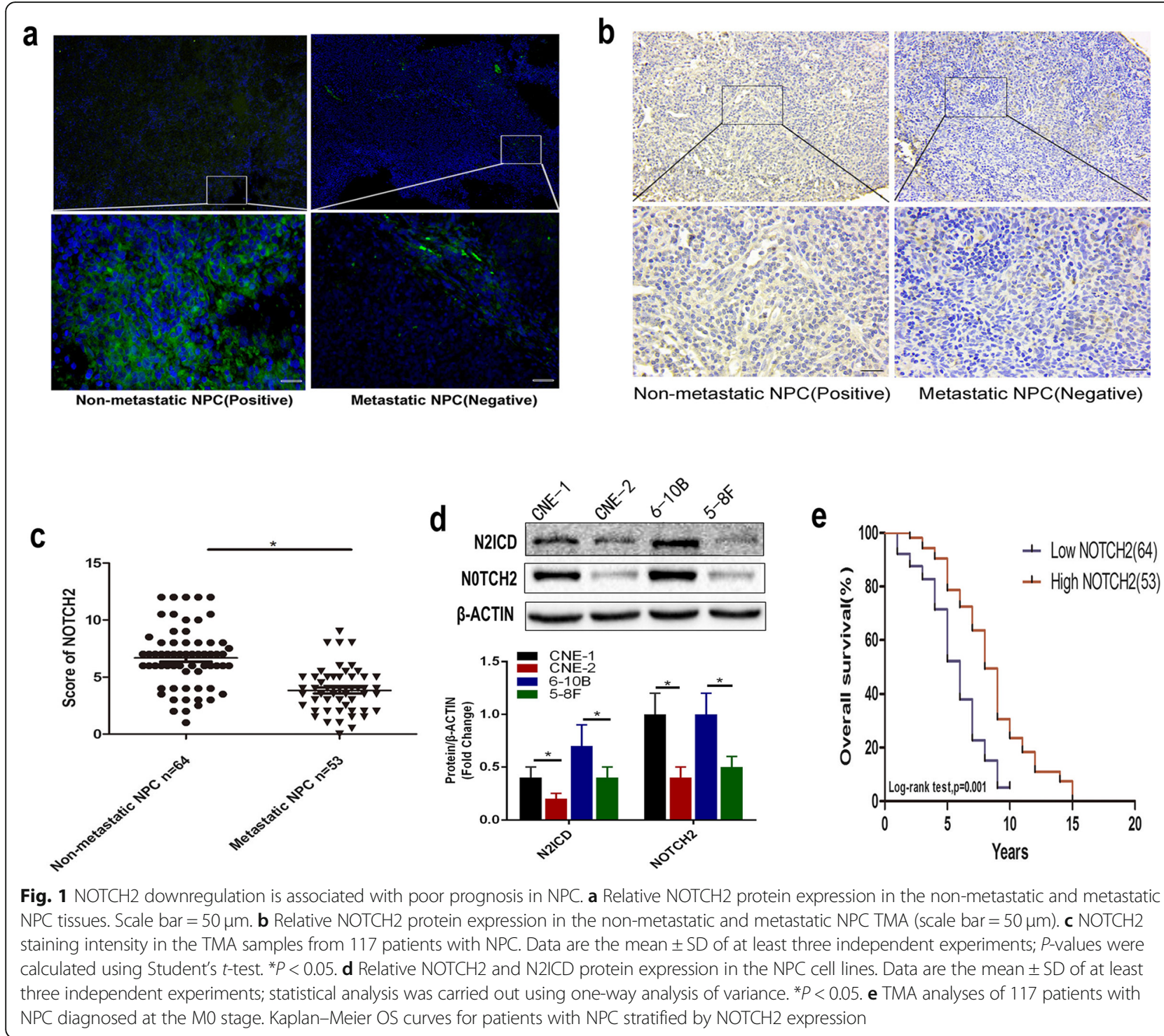


tumors $[19,20]$. Chen et al. found that TRAF6 promotes head and neck cancer metastasis by regulating cancer stem cells (CSCs) through NF-kB signaling [20].

Epithelial-mesenchymal transformation (EMT) is the process by which epithelial cells transform and acquire an invasive mesenchymal phenotype. In tumor cells, EMT is an important step in tumor progression and metastasis. Many studies have found that the acquisition of mesenchymal cell characteristics of tumor cells is closely related to an enhanced invasive ability, that is, this process can promote the invasion and metastasis of tumor cells [21].

In this study, we used the CNE-2 and 5-8F NPC cell lines to represent the main phenotypes of NPC [22]. We investigated the expression of NOTCH2 in human NPC tissues and explored the effects of silencing and overexpressing $\mathrm{NOTCH} 2$ on the metastasis of NPC cells in vitro and in vivo. Mechanistically, $\mathrm{NOTCH} 2$ inhibited AKT signaling activation by binding to TRAF6 to suppress NPC metastasis. Our investigations indicate that $\mathrm{NOTCH} 2$ functions as a tumor suppressor by attenuating the TRAF6/AKT signaling cascade in NPC.

\section{Materials and methods}

\section{Human tissue samples}

Thirty paraffin-embedded NPC biopsy samples with known clinical characteristics were collected from the Department of Pathology, Renmin Hospital of Wuhan University. The samples were from 15 patients without cervical lymph node metastasis and 15 patients with cervical lymph node metastasis. The NPC tissue microarray (TMA), along with the detailed clinical characteristics and long-term follow-up data, was procured from Guilin Fanpu Biotech (Guilin, China, production no. 1501 and 1502). The TMA contained 64 NPC tissue samples without cervical lymph node metastasis and 53 NPC tissue samples with cervical lymph node metastasis. None of the patients had received any antitumor therapy before biopsy. The Institutional Ethical Review Board of Renmin Hospital of Wuhan University approved the research protocols.

\section{Immunofluorescence analysis}

Immunofluorescence analysis was performed as described previously [23]. The samples were incubated overnight at $4{ }^{\circ} \mathrm{C}$ with primary antibodies. Rabbit NOTCH2 antibodies (\#5732) from CST (Danvers, MA, USA) were used. After the sections were washed, they were incubated with fluorescence-labeled secondary antibodies for $1 \mathrm{~h}$ in the dark. After a final wash, the coverslips were mounted with antifade reagent with 4 , 6-diamidino-2-phenylindole (DAPI, \#P36935, Life Technologies, Grand Island, NY, USA).
Cells were cultured on coverslips in 24-well plates for $24 \mathrm{~h}$, fixed for $15 \mathrm{~min}$ in $4 \%$ paraformaldehyde, washed three times with PBS, permeabilized in $0.2 \%$ Triton X100 in PBS, incubated with primary antibodies overnight at $4{ }^{\circ} \mathrm{C}$, washed with PBS, incubated with secondary antibody at $37^{\circ} \mathrm{C}$ for $1 \mathrm{~h}$, washed with PBS, and counterstained with DAPI.

\section{Immunohistochemical analysis}

The tissue samples were analyzed using immunohistochemistry. The samples were subjected to high-pressure antigen retrieval in pH 6.0 citrate buffer for $5 \mathrm{~min}$, blocked with $10 \%$ bovine serum albumin for $60 \mathrm{~min}$, and incubated overnight at $4{ }^{\circ} \mathrm{C}$ with primary antibodies, followed by anti-rabbit peroxidase-conjugated secondary antibodies (1:500). Rabbit NOTCH2 antibodies (\#5732) from CST were used.

The sections were independently scored by two pathologists. The staining index was determined for each sample as the product of the staining intensity ( 0 , no staining; 1, weak staining, light yellow staining; 2, moderate, yellow brown staining; 3 , strong, brown staining) and the proportion of positive cells $(1,<10 \% ; 2,10-35 \%$; $3,35-70 \%, 4,>70 \%)$ [24].

\section{Cell lines}

The CNE-1 and CNE-2 cells were obtained from the China Center for Type Culture Collection (Wuhan, China). The 6-10B and 5-8F cells were obtained from Southern Medical University (Guangzhou, China). The four NPC cell lines (CNE-1, CNE-2, 5-8F, 6-10B) were cultured in RPMI 1640 medium $(11,879,020$, Life Sciences, Logan, UT, USA) containing $10 \%$ fetal bovine

Table 1 Clinical characteristics of the patients with NPC stratified by NOTCH2 expression

\begin{tabular}{|c|c|c|c|c|}
\hline & \multicolumn{2}{|c|}{ NOTCH2 expression } & \multirow[t]{2}{*}{ Total } & \multirow[t]{2}{*}{$P$-value } \\
\hline & Low $(n=64)$ & High $(n=53)$ & & \\
\hline Age, years & & & & 0.462 \\
\hline$<50$ & 44 & 33 & 77 & \\
\hline$\geq 50$ & 20 & 20 & 40 & \\
\hline Sex & & & & 0.567 \\
\hline Male & 50 & 39 & 89 & \\
\hline Female & 14 & 14 & 28 & \\
\hline HBV & & & & 0.625 \\
\hline Positive & 61 & 52 & 113 & \\
\hline Negative & 3 & 1 & 4 & \\
\hline Metastasis & & & & $<0.001$ \\
\hline No & 17 & 47 & 64 & \\
\hline Yes & 47 & 6 & 53 & \\
\hline
\end{tabular}

$P$-values were calculated using the chi-square test or Fisher's exact test; significance was defined as $P$-values of $<0.05$. HBV, Hepatitis B virus 

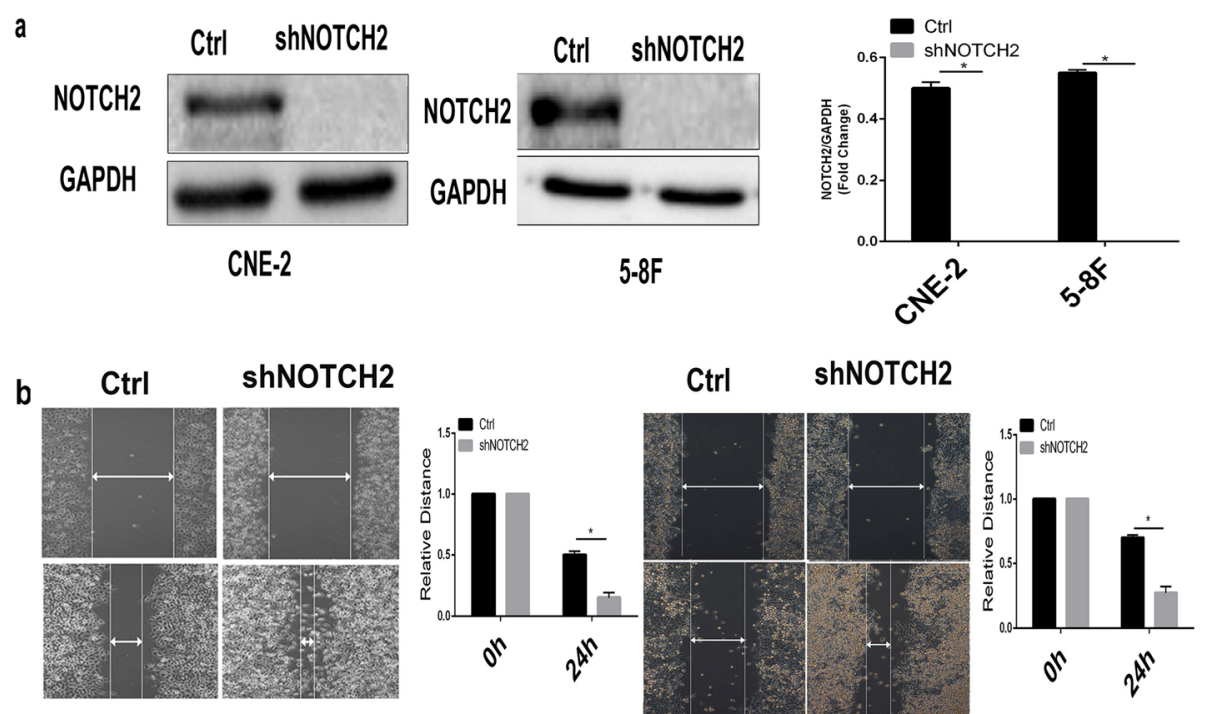

CNE-2

$5-8 \mathrm{~F}$
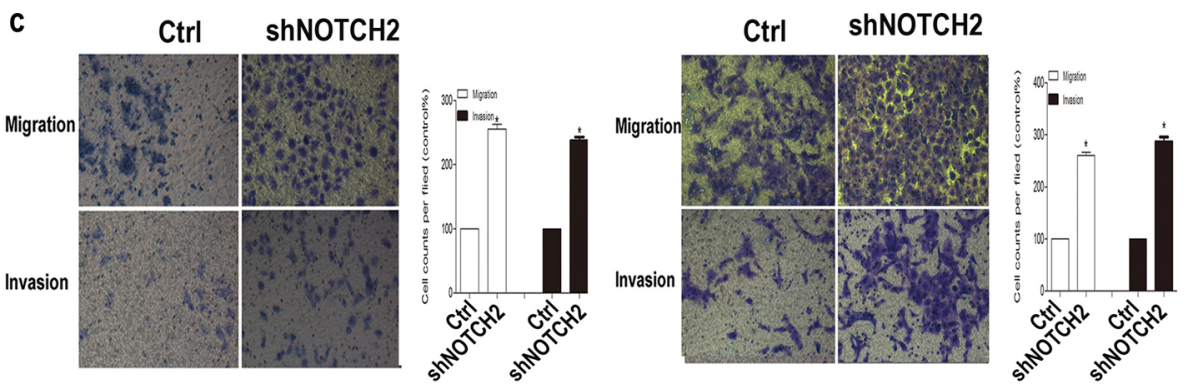

CNE-2

5-8F
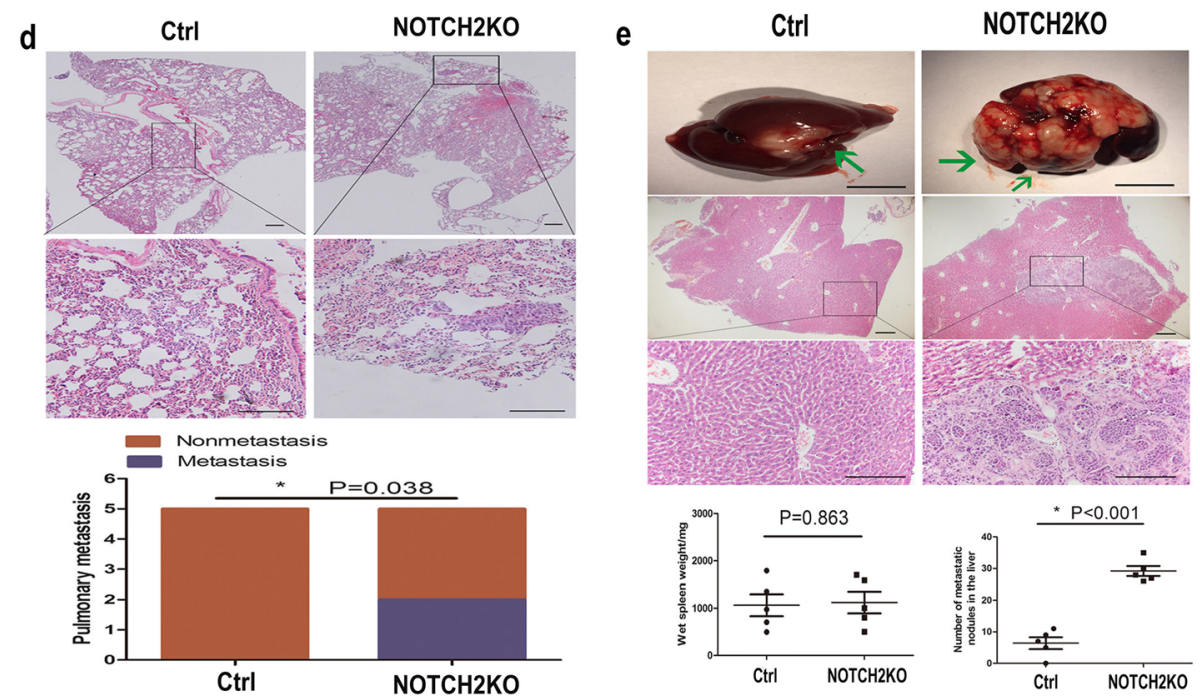

Fig. 2 (See legend on next page.) 
(See figure on previous page.)

Fig. 2 Suppression of NOTCH2 promotes NPC cell metastasis. a shNOTCH2 cells were established. Western blotting confirmed the knockdown of $\mathrm{NOTCH} 2$ in CNE-2 and 5-8F cells. b Wound healing assays showed that knockdown of NOTCH2 increased the CNE-2 and 5-8F cell migration distance. Right panel: Quantification of the gap closure. c Transwell migration assays showed that knockdown of NOTCH2 increased the CNE-2 and 5-8F cell migration. Transwell invasion assays showed that knockdown of NOTCH2 increased the CNE-2 and 5-8F cell invasion. Data are the mean \pm SD of at least three independent experiments; ${ }^{*} P<0.05$, Student's $t$-test. $\mathbf{d}$ The NOTCH2KO group had significantly more nude mice with lung metastasis than the Ctrl group. First and second panel: Representative hematoxylin and eosin (H\&E) staining of the lungs. Third panel: Quantification of nude mice with lung metastasis. Scale bar $=50 \mathrm{~mm}$. P-values were calculated using the $x^{2}$ test. e Mice in the NOTCH2KO group had significantly more metastatic lesions on the liver surface than mice in the Ctrl group. First panel: Macroscopic metastatic nodules on the surface of the liver (scale bar $=1 \mathrm{~cm}$ ). Second and third panel: Representative H\&E staining of the livers; scale bar $=50 \mathrm{~mm}$. Fourth panel:

Quantification of metastases on the liver surface. P-values were calculated using Student's t-test. Arrows indicate surface metastatic nodules

serum (FBS; Gibco; Thermo Fisher Scientific, Waltham, MA, USA 10100147) in a humidified atmosphere containing $5 \% \mathrm{CO}_{2}$ at $37^{\circ} \mathrm{C}$.

A CRISPR/Cas9 system was used to establish stable NOTCH2KO cells. The target sequence for human NOTCH2 was 5'-TTTCCATACAGATGTCCAGA-3' (at the intron 2/exon 3 boundary). Complementary oligonucleotides with BpiI restriction sites for guide RNAs were cloned into the guide RNA-Cas9 vector (Biocytogen Co., Ltd., Beijing, China) to generate the NOTCH2Cas9 construct, which was then used to transfect the CNE-2 cells. The genome sequences of the edited locus in selected colonies were confirmed by sequencing analyses; NOTCH2 protein levels in the colonies were tested by Western blotting.

Cells $\left(2 \times 10^{5}\right)$ were seeded in 6-well plates, transduced with mixtures of lentiviruses carrying the sgRNAs, and cultured for $12 \mathrm{~h}$, and then, the medium was changed to fresh RPMI-1640 containing 10\% FBS. The transduced cells were selected through culture for 6 days in media containing $0.5 \mu \mathrm{g} / \mathrm{mL}$ puromycin (A1113802, Thermo Fisher Scientific, Waltham, MA, USA) and then maintained in regular culture media.

NOTCH2 fragments (5'-TGGTGACCGAGATC CTGAAG-3'), short hairpin RNA (shRNA) targeting TRAF6 (shTRAF6) (5'-GCGCTGTGCAAACTATATATC-3') and shRNA targeting NOTCH2 (shNOTCH2) (5'-TGGAGG TCTCAGTGGATATAA-3') were inserted into the lentiviral vector (Shanghai HeYuan, Shanghai, China). Similar empty control lentivirus vectors served as the controls.

NOTCH2-overexpressing cells (oeNOTCH2) and $\mathrm{NOTCH} 2$ knockdown cells (shNOTCH2) were established. The day before transfection, NPC cells in good condition were inoculated into 6-well plates. When the degree of cell fusion reached $70-80 \%$, the culture medium was removed, and $1 \mathrm{~mL}$ of complete culture medium containing viruses $(\mathrm{MOI}=8)$ was added. Polybrene was added to each well to facilitate the transfection (final concentration was $6 \mu \mathrm{g} / \mathrm{ml}$ ). After $8 \mathrm{~h}$ of transfection, the culture medium containing the virus was removed, and complete culture medium was added. Twenty-four hours after transfection, the culture medium was removed, and complete culture medium containing $0.6 \mu \mathrm{g} / \mathrm{ml}$ puromycin was added. The solution was changed every $48 \mathrm{~h}$, and complete medium with the original concentration of puromycin was added; the culture continued for 10 days to ensure the drugs were effective.

shNOTCH2 + shTRAF6 CNE-2 cells were established. The day before transfection, NPC cells in good condition were inoculated into 6-well plates. When the degree of cell fusion reached $70-80 \%$, the culture medium was removed, and $1 \mathrm{~mL}$ of complete culture medium containing both viruses $(\mathrm{MOI}=8)$ was added. Polybrene was added to each well to facilitate transfection (final concentration was $6 \mu \mathrm{g} / \mathrm{m} 1)$. After $8 \mathrm{~h}$ of transfection, the culture medium containing the virus was removed, and complete culture medium was added. Twenty-four hours after transfection, the culture medium was removed, and complete culture medium containing $0.6 \mu \mathrm{g} / \mathrm{ml}$ puromycin (screening of NOTCH2) and $400 \mu \mathrm{g} / \mathrm{ml} \mathrm{G} 418$ (screening of TRAF6) was added. The solution was changed every $48 \mathrm{~h}$, and complete medium with the original concentrations of puromycin and G418 was added; the culture continued for 10 days to ensure the drugs were effective.

\section{In vitro invasion and migration assays}

For the scratch wound-healing motility assay, cells were grown to confluence in 6-well culture plates, 'scratch' wounds were created using $10 \mu \mathrm{L}$ pipette tips, and then, the cells were incubated for $24 \mathrm{~h}$, washed twice with fresh media to remove nonadherent cells and imaged by light microscopy. The ratio of the size of the gap after $24 \mathrm{~h}$ to the size of the gap at the start of the experiment was treated as the relative migration. Data representative of three independent experiments are presented.

For the Transwell invasion assay, cells were serum starved for $8 \mathrm{~h}$, seeded onto the upper chambers of Transwell inserts precoated with Matrigel $(2.5 \mathrm{mg} / \mathrm{mL}$; BD Biosciences, San Jose, USA 354230) in RPMI-1640 containing 3\% FBS $\left(1.0 \times 10^{5}\right.$ cells/well), and $800 \mu \mathrm{L}$ of RPMI-1640 supplemented with 10\% FBS was added to the lower chambers. The migration assay protocol was exactly the same as the invasion assay protocol, except the Transwell membranes were not coated with Matrigel. After $48 \mathrm{~h}$, the membranes were swabbed clean. 

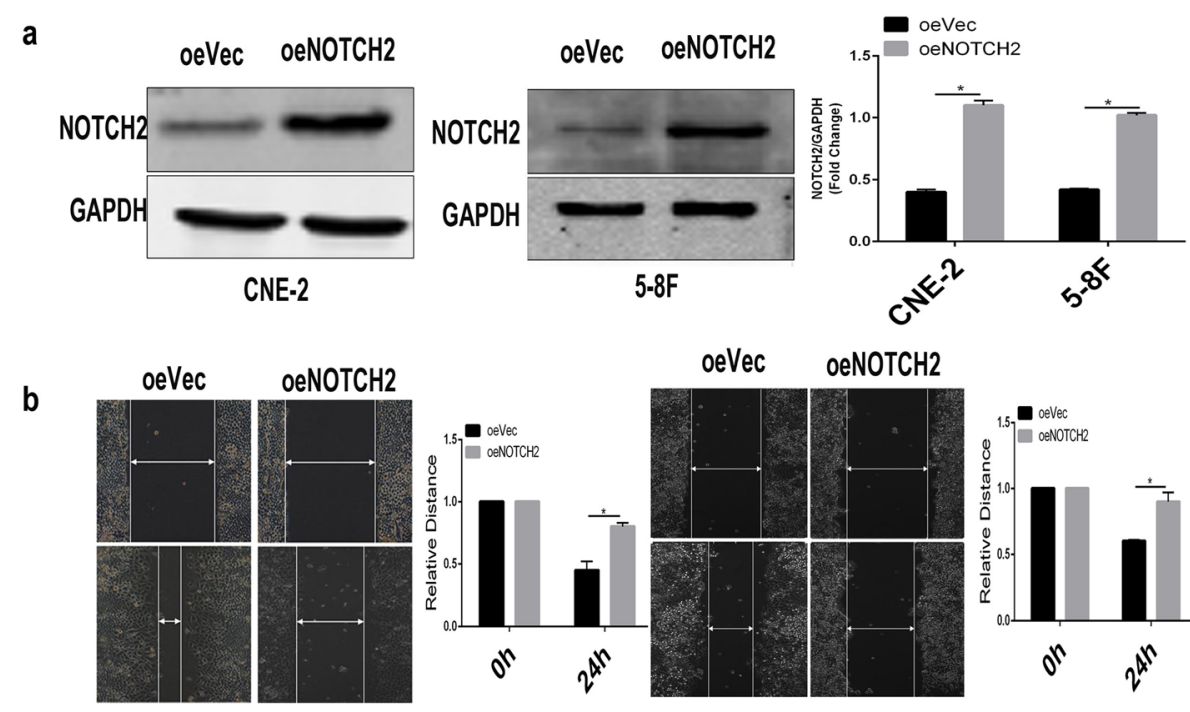

oeVec

oeNOTCH2

CNE-2
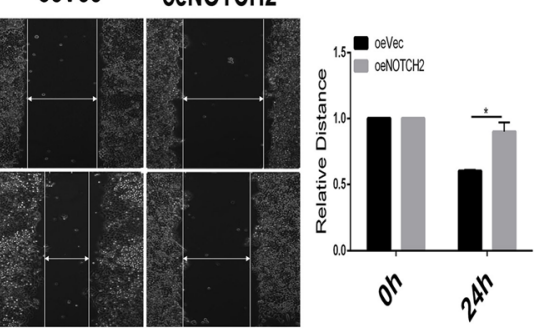

$5-8 \mathrm{~F}$

C
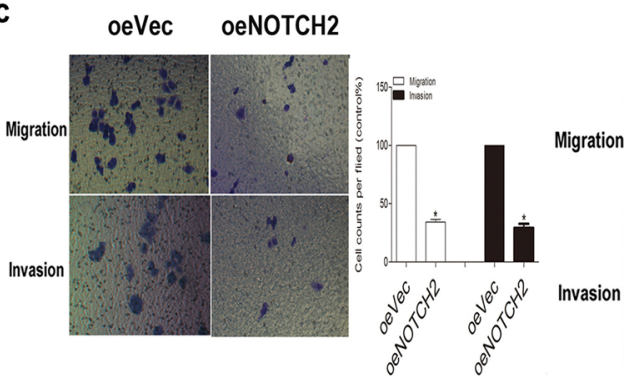

oeVec oeNOTCH2

CNE-2
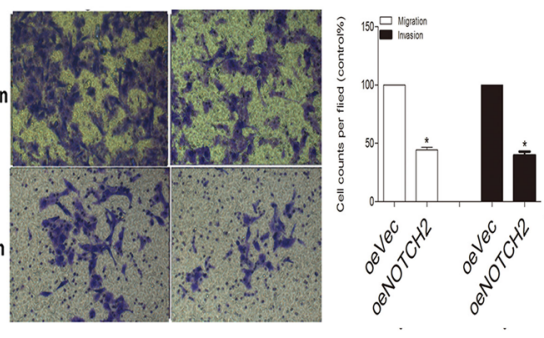

$5-8 \mathrm{~F}$

d

e oeNOTCH2 oeVec
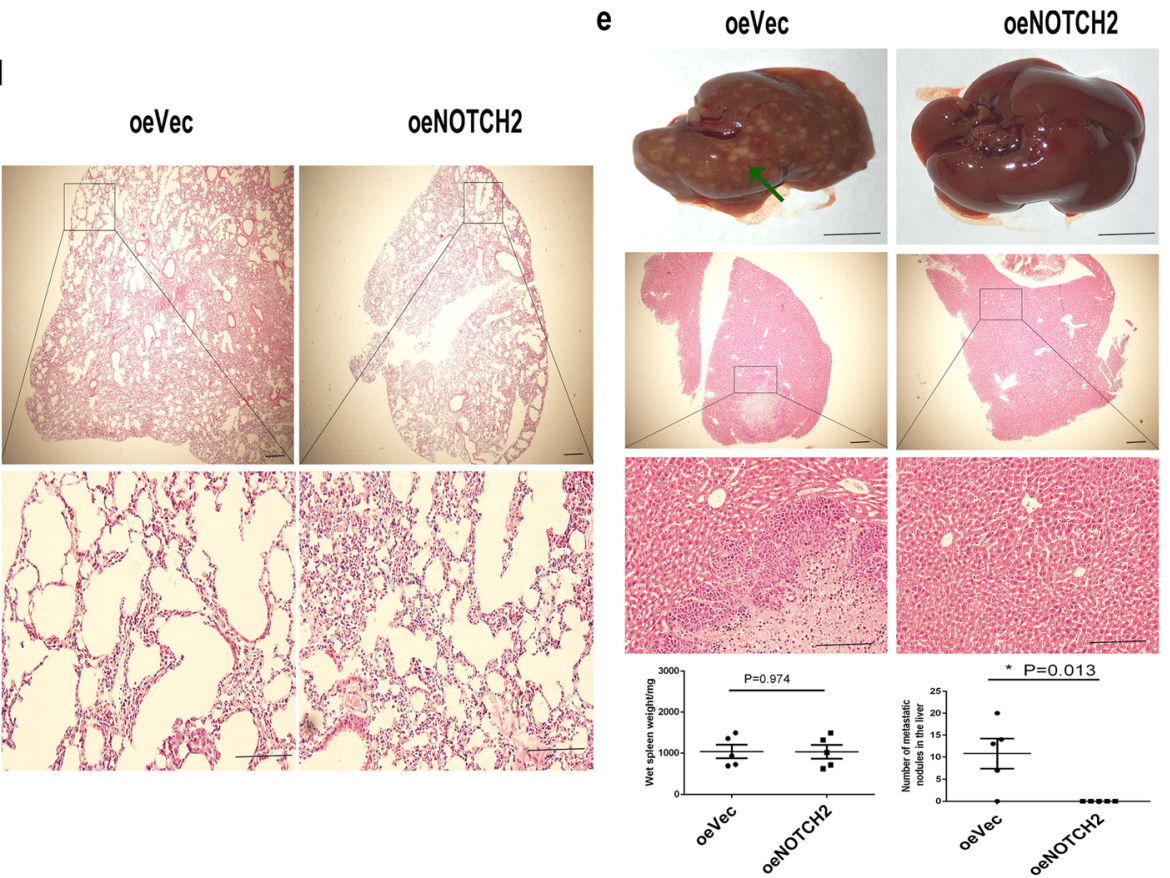

Fig. 3 (See legend on next page.) 
(See figure on previous page.)

Fig. 3 Overexpression of NOTCH2 inhibits NPC cell metastasis. a oeNOTCH2 cells were established. Western blotting confirmed the overexpression of NOTCH2 in CNE-2 and 5-8F cells. b Wound healing assays showed that overexpression of NOTCH2 inhibited the CNE-2 and 58F cell migration distance. Right panel: Quantification of the gap closure. c Transwell migration assays showed that overexpression of NOTCH2 inhibited the CNE-2 and 5-8F cell migration. Transwell invasion assays showed that overexpression of NOTCH2 inhibited the CNE-2 and 5-8F cell invasion. Data are the mean \pm SD of at least three independent experiments; ${ }^{*} P<0.05$, Student's $t$-test. $\mathbf{d}$ The oeNOTCH 2 and oeVec groups did not develop lung metastasis. Representative H\&E staining of the lung is shown. Scale bar $=50 \mathrm{~mm}$. e The oeNOTCH2 group had significantly fewer metastatic lesions on the liver surface than the oeVec group. First panel: Macroscopic metastatic nodules on the surface of the liver (scale bar $=1 \mathrm{~cm}$ ). Second and third panel: Representative H\&E staining of the liver (scale bar $=50 \mathrm{~mm}$ ). Fourth panel: Quantification of metastases on the liver surface. $P$-values were calculated using Student's $t$-test. Arrows indicate surface metastatic nodules

Invaded/migrated cells were stained with crystal violet, and the numbers of cells in three or four fields on each filter were counted under a light microscope. Data representative of three independent experiments are presented.

\section{Western blotting}

The Western blotting procedure has been described previously [25]. The antibodies used were rabbit antiGAPDH (\#5174), anti-full-length NOTCH2 (\#5732), anti- $\beta$-actin (\#8457), anti-TRAF6 (\#8028), anti-ERK (\#4370), anti-P38, anti-P70S6K (\#2708), anti-MTOR (\#2983), anti-SMAD3 (\#9523), anti-AKT (\#4685), antivimentin (\#5741), anti-E-cadherin (\#3195), anti-PI3K (\#4249), anti-phospho-ERK1/2 (\#4370), anti-phosphoJNK1/2 (\#4668), anti-phospho-P38 (\#4511), antiphospho-AKT (\#4060), anti-phospho-P70S6K (\#9234), anti-phospho-MTOR (\#5536), anti-phospho-TBK1 (\#5483), anti-JNK (\#9252), and anti-TBK1 (\#3504) purchased from CST (Beverly MA, USA); anti-NOTCH2 intracellular domain (\#Q04721) from R\&D Systems (Minneapolis, MN, USA); anti-phospho-PI3K (ab32089) from Abcam (Cambridge, MA, USA); and anti-rabbit secondary antibodies (926-32,219) from Li-Cor Biosciences (Lincoln, NE, USA).

\section{Flow cytometry}

The cells $\left(1 \times 10^{6}\right)$ were trypsinized, washed in phosphate-buffered saline, resuspended in $100 \mathrm{~mL}$ Staining Buffer (eBioscience, San Diego, CA, USA) containing $1 \%$ FBS, incubated on ice for 20 min to block Fc receptors, then incubated with a primary phycoerythrin (PE) anti-human CD133 (130-102-834, Miltenyi Biotec, Auburn, USA) for $45 \mathrm{~min}$ on ice in the dark, washed twice with $1 \mathrm{~mL}$ ice-cold staining buffer, centrifuged at $400 \mathrm{~g}$, resuspended in $0.5 \mathrm{~mL}$ of $2 \%$ formaldehyde fixation buffer and analyzed using a FACSCalibur flow cytometer with CellQuest software (BD Biosciences, San Jose, USA). Three independent experiments were performed in triplicate.

\section{Phalloidin staining}

Cells were cultured for $24 \mathrm{~h}$, fixed in $4 \%$ formalin for 20 min, washed three times with phosphate-buffered saline (PBS), and stained with $5 \mu \mathrm{g} / \mathrm{mL}$ of phalloidin conjugate solution (P5282, Sigma, Carlsbad, CA, USA) in PBS for $40 \mathrm{~min}$ at $37^{\circ} \mathrm{C}$. The cells were washed three times with PBS to remove the unbound phalloidin conjugate and imaged by confocal laser-scanning microscopy (Fluoview 1000; Olympus, Tokyo, Japan).

\section{Mouse tumor metastatic dissemination models}

For the metastasis assay, 5-6-week-old male nude mice (Vital River Laboratory Animal Technology, Beijing, China) were anesthetized using isoflurane and underwent laparotomies, and $2 \times 10^{5}$ cells in $30 \mathrm{~mL}$ of RPMI 1640 medium containing 33\% Matrigel were injected into the spleen. The mice were euthanized after 28 days; the livers, spleens, and lungs were excised; the metastatic nodules in the livers and lungs were counted; and the livers and lungs were processed for hematoxylin and eosin (H\&E) staining [26].

\section{Gene set enrichment analysis}

The GSE 12452 [27] and GSE 13597 [28] datasets were downloaded from the Gene Expression Omnibus (GEO) database. Genes potentially influenced by $\mathrm{NOTCH} 2$ were identified using the Java gene set enrichment analysis (GSEA) program (http://www.broadinstitute.org/ gsea). The patients in the GSE12452 dataset were classified into two groups according to NOTCH2 expression (top 50\%: high vs. bottom 50\%: low). GSEA was used to assess the effects of $\mathrm{NOTCH} 2$ expression on various gene sets; significance was defined as $P<0.05$.

\section{Reagents}

An AKT signaling inhibitor (LY294002, \#9910) from CST was dissolved in dimethyl sulfoxide (DMSO), stored at $-20{ }^{\circ} \mathrm{C}$, and diluted in medium. The final concentration of DMSO was $\leq 0.1 \%$ in all experiments. Cells were seeded in 6-well plates $\left(3 \times 10^{5}\right.$ cells/well $)$ and treated for $24 \mathrm{~h}$ with specific inhibitors against AKT (final concentration, $20 \mu \mathrm{M}$ ). G418 (A1720) and puromycin (P9620) were from Sigma (Carlsbad, CA, USA).

\section{Immunoprecipitation assay}

Cultured CNE-2 cells were collected and sonicated in IP buffer $(20 \mathrm{mM}$ Tris- $\mathrm{HCl} \mathrm{pH} 8.0,150 \mathrm{mM} \mathrm{NaCl}, 1 \mathrm{mM}$ EDTA, $0.5 \%$ NP-40) supplemented with protease 
a
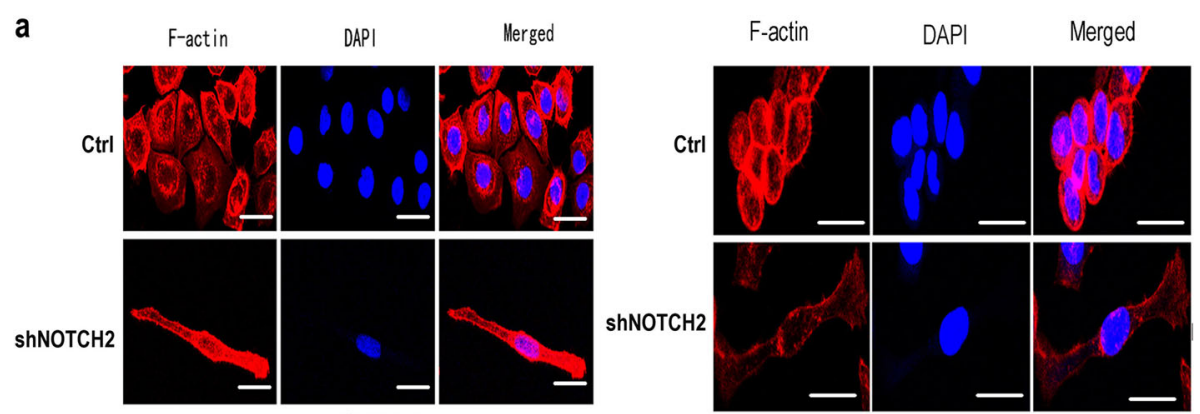

CNE-2

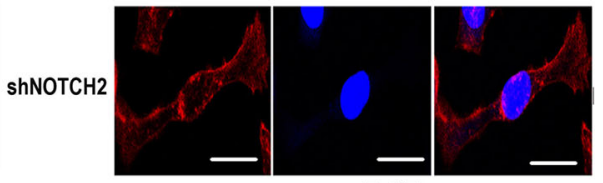

5-8F

b

Ctrl
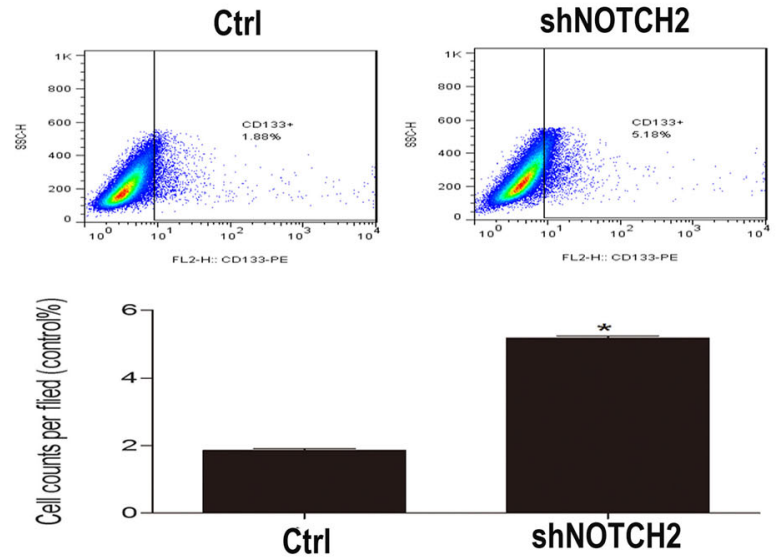

c
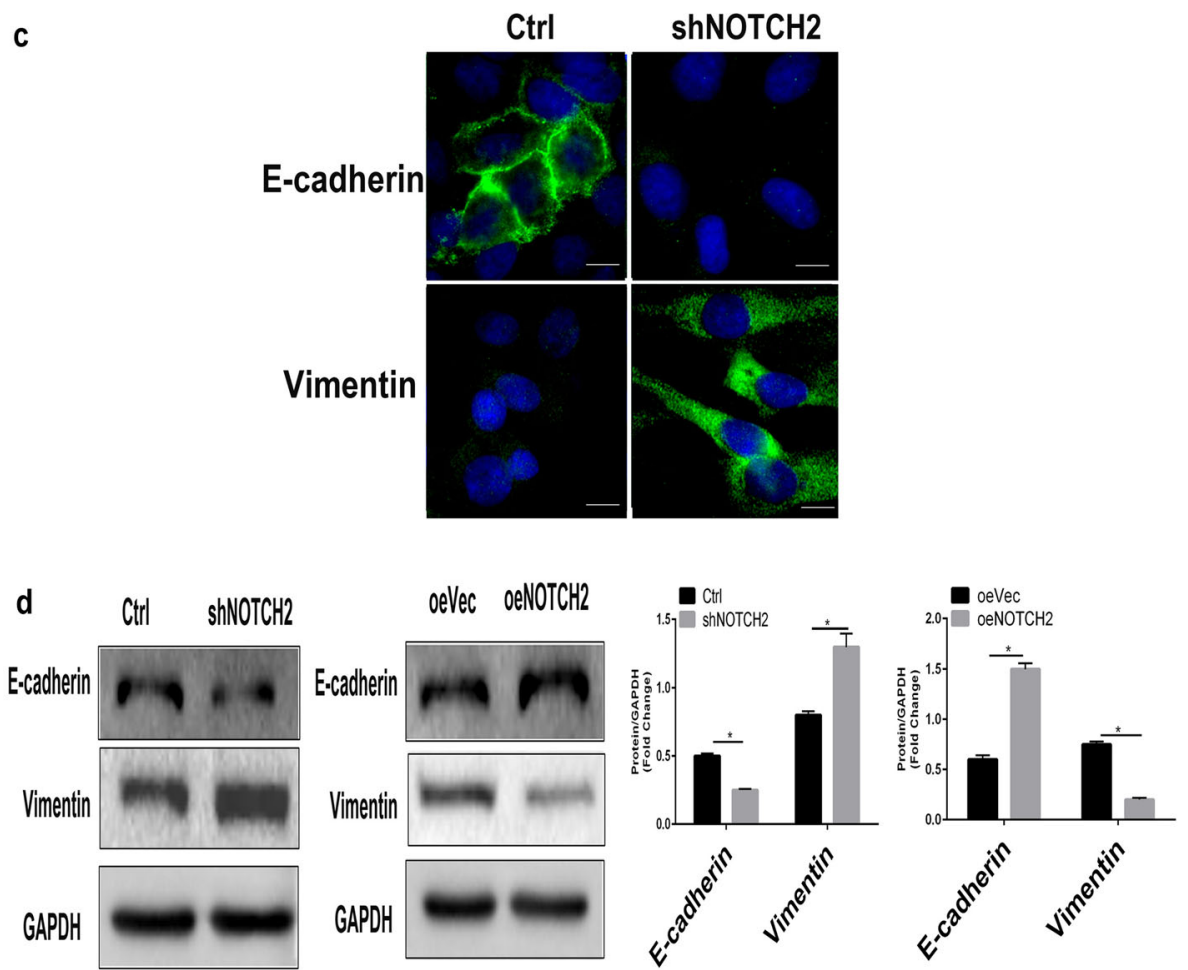

Fig. 4 (See legend on next page.) 
(See figure on previous page.)

Fig. 4 NOTCH2 represses EMT in NPC. a Morphological alterations were confirmed by staining for the CNE-2 and 5-8F cell cytoskeletal proteins. b Flow cytometric analysis. shNOTCH2 CNE-2 cells contained an increased proportion of CD133 ${ }^{+}$cells. ${ }^{*} P<0.05$ vs. Ctrl cells, one-way ANOVA. c Immunofluorescence showed that suppression of $\mathrm{NOTCH} 2$ increased vimentin expression and decreased E-cadherin expression. $\mathbf{d}$ Western blots showed that suppression of NOTCH2 increased vimentin expression and decreased E-cadherin expression; NOTCH2 overexpression decreased vimentin expression and increased E-cadherin expression. ${ }^{*} P<0.05$, Student's $t$-test. Scale bars $=50 \mu \mathrm{m}$

inhibitor cocktail (04693132001, Roche, Basel, Switzerland). After a 20 -min incubation at $4{ }^{\circ} \mathrm{C}$, followed by a 15 -min centrifugation at $13,000 \times g$, the cell lysates were precleared with normal mouse or rabbit immunoglobulin G and protein A/G-agarose beads $(11,719,394$, $001,11,719,386,001$, Roche) for $3 \mathrm{~h}$ at $4{ }^{\circ} \mathrm{C}$. The lysates $(500 \mu \mathrm{L})$ were then incubated with $1 \mu \mathrm{g}$ of the antibody and $10 \mu \mathrm{L}$ of protein $\mathrm{A} / \mathrm{G}$-agarose beads on a rocking platform at $4{ }^{\circ} \mathrm{C}$ overnight. The immunocomplex was collected, washed 5-6 times with cold IP buffer, and blotted using the indicated primary antibodies. For determination of the specificity of the bands on the immunoblots, IgG (negative control) and N2ICD antibody (positive control) were used as the immunoprecipitants.

\section{Statistical analysis}

GraphPad Prism 5 (La Jolla, CA, USA) was used for statistical analyses. The results are presented as the mean \pm SD (standard deviation) of three independent experiments. Student's $t$-test was used to compare control and NOTCH2 knockdown or NOTCH2-overexpressing cells. The relationships between $\mathrm{NOTCH} 2$ staining intensity and clinicopathological characteristics were assessed using Pearson's chi-square or Fisher's exact test. Survival curves were plotted using the Kaplan-Meier method and compared using the log-rank test; $P<0.05$ was defined as significant.

\section{Results \\ NOTCH2 expression levels are associated with NPC metastasis and patient survival}

We previously showed that $\mathrm{NOTCH}$ signaling accelerated growth, local invasion and metastasis in NPC [15]; therefore, we subsequently explored the role of the individual NOTCH receptors in NPC. We evaluated $\mathrm{NOTCH} 2$ protein levels using biopsy samples from patients with NPC and a tissue microarray (TMA) containing NPC tissues. We found decreased NOTCH2 protein levels in the NPC biopsy samples and the TMA samples with cervical lymph node metastasis. In contrast, $\mathrm{NOTCH} 2$ protein levels were increased in the nonmetastatic NPC tissues (Fig. 1a-b). NOTCH2 was downregulated in NPC tissues with metastasis (Fig. 1c).

In addition, NOTCH2 and N2ICD levels were reduced in the poorly differentiated NPC cells (CNE-2) compared with the highly differentiated NPC cells (CNE-1) and in the highly metastatic NPC cells (5-8F) compared with the poorly metastatic NPC cells $(6-10 \mathrm{~B}) \quad(P<0.05$; Fig. 1d). An optimal cutoff value (staining index: 5.75) for high and low NOTCH2 expression was identified using receiver operating characteristic (ROC) curve analysis [29]. Our results indicated that low NOTCH2 expression is associated with significantly poorer overall survival than high $\mathrm{NOTCH} 2$ expression (OS; hazard ratio $[\mathrm{HR}], 2.977 ; 95 \%$ confidence interval $[\mathrm{CI}], 1.751-$ 5.061; $P=0.001, P<0.05)$ (Fig. 1e).

Table 1 summarizes the general information for the 64 patients with NPC without cervical lymph node metastasis and the 53 patients with NPC with cervical lymph node metastasis. An obvious association was detected between low NOTCH2 expression and cervical lymph node metastasis $(P<0.05)$. NOTCH2 expression and other clinical features were not significantly correlated.

\section{Suppression of NOTCH2 promotes NPC cell metastasis}

We generated NOTCH2 knockdown CNE-2 and 5-8F cells (shNOTCH2 cells) to assess the biological function of NOTCH2 in NPC. Western blotting confirmed that stable shNOTCH2 cells had been successfully established $(P<0.05$; Fig. 2a). Knockdown of NOTCH2 significantly promoted $\mathrm{CNE}-2$ and $5-8 \mathrm{~F}$ cell migration (Fig. $2 b)$ and invasion in vitro $(P<0.05$; Fig. 2 c), indicating that NOTCH2 suppression promotes NPC cell metastasis in vitro.

A murine metastasis model was used to assess the role of NOTCH2 in NPC cell metastasis in vivo. Nude mice in the NOTCH2KO CNE-2 cell group had significantly more lung metastases than those in the Ctrl CNE-2 cell group (the Ctrl CNE-2 cell group had no lung metastasis) $(P<0.05$; Fig. 2 d). Mice injected with NOTCH2KO CNE-2 cells developed significantly more metastatic foci in the liver than mice injected with Ctrl CNE-2 cells with no altered primary tumor growth in the spleen $(P<$ 0.05 ; Fig. 2e), indicating that $\mathrm{NOTCH} 2$ suppression promotes NPC cell metastasis in vivo.

\section{Overexpression of NOTCH2 inhibits NPC cell metastasis} We also overexpressed NOTCH2 in CNE-2 and 5-8F cells using a lentiviral vector. Western blotting confirmed that stable oeNOTCH2 (NOTCH2 overexpression) cells had 


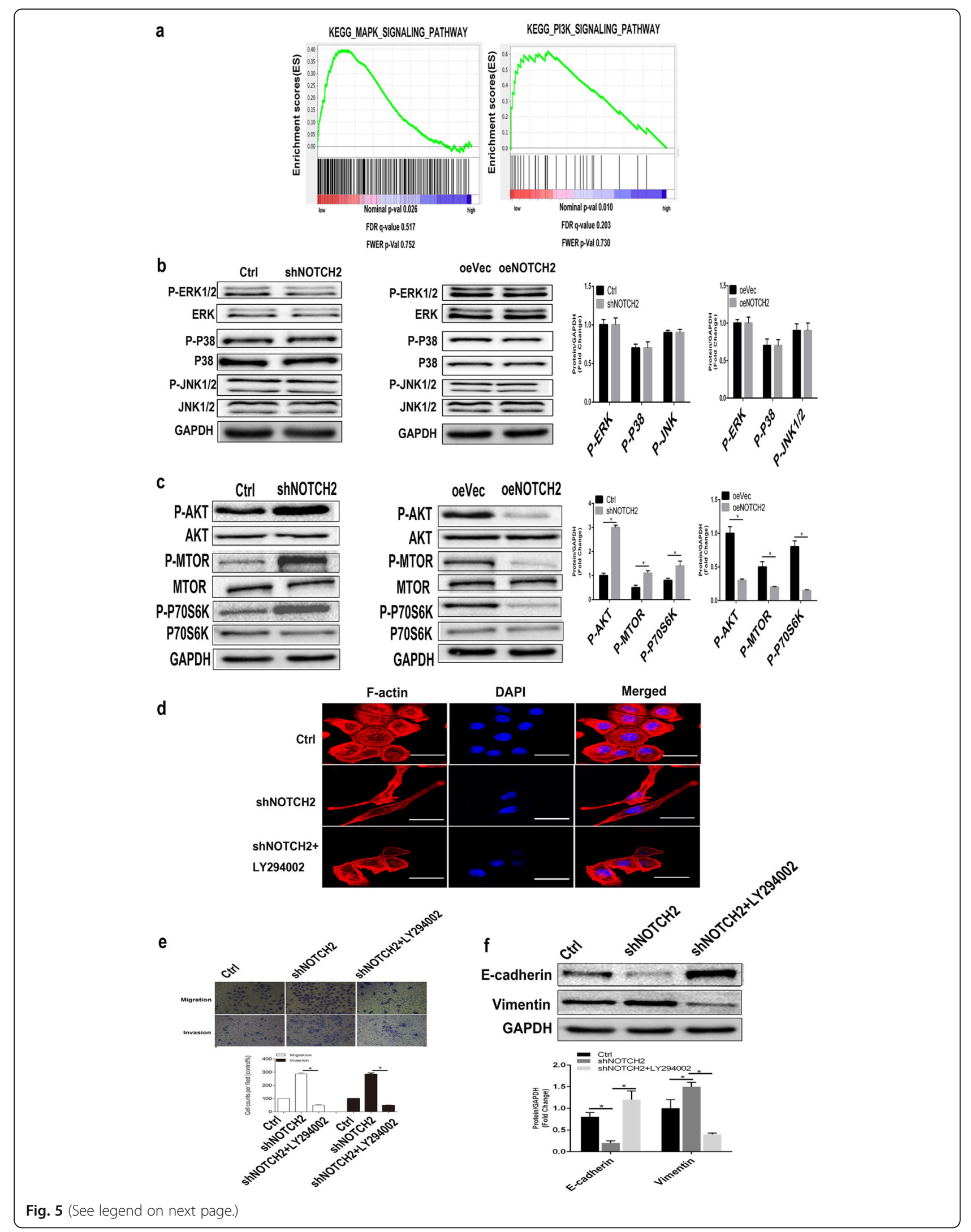


(See figure on previous page.)

Fig. 5 Loss of NOTCH2 promotes EMT in NPC cells by activating AKT signaling. a A GSEA plot showed that the MAPK signaling pathway $(P=0.026<0.05)$ and PI3K signaling pathway $(P=0.010<0.05)$ were gradually inhibited as NOTCH2 expression increased in patients with NPC. $\mathbf{b}$ Western blots showing that abnormal expression of NOTCH2 did not alter MAPK signaling component activity. $P>0.05$, Student's $t$-test. $\mathbf{c}$ Western blots showing that NOTCH2 knockdown increased AKT/MTOR/P70s6K signaling component activity and that overexpression of NOTCH2 had the opposite effects. *P<0.05, Student's ttest. $\mathbf{d}$ Representative images of the cytoskeleton (red) and DAPI (blue) in the indicated CNE-2 cells after $24 \mathrm{~h}$ of treatment with the AKT inhibitor LY294002. e Transwell invasion assays showing that the AKT inhibitor reduced shNOTCH2 cell invasion in vitro. ${ }^{*} P<0.05$, one-way ANOVA. (f) Compared with the shNOTCH2 group, the shNOTCH2 + LY294002 group had downregulated vimentin expression and upregulated E-cadherin expression. ${ }^{*} P<0.05$, one-way ANOVA. Scale bars $=50 \mu \mathrm{m}$

been successfully established $(P<0.05$; Fig. 3a). Overexpression of NOTCH2 significantly inhibited $\mathrm{CNE}-2$ and 58 F cell migration $(P<0.05$; Fig. $3 \mathrm{~b})$ and invasion in vitro $(P<0.05$; Fig. $3 c)$, indicating that $\mathrm{NOTCH} 2$ overexpression inhibits NPC cell metastasis in vitro.

A murine metastasis model was used to assess the role of NOTCH2 in NPC cell metastasis in vivo. Mice injected with oeVec 5-8F cells and oeNOTCH2 5-8F cells did not develop lung metastasis (Fig. 3d).

Mice injected with oeNOTCH2 5-8F cells developed significantly fewer metastatic foci in the liver than mice injected with oeVec 5-8F cells with no alteration of primary tumor growth in the spleen $(P<0.05$; Fig. 3e), indicating that $\mathrm{NOTCH} 2$ overexpression inhibits NPC cell metastasis in vivo.

\section{NOTCH2 represses epithelial-mesenchymal transition (EMT) in NPC cells}

shNOTCH2 CNE-2 and 5-8F cells exhibited an elongated, spindle-like, fibroblastic cellular morphology with F-actin fibers visible in immunofluorescence (IF) analysis, whereas Ctrl cells had a cobblestone-like appearance typical of normal epithelial cells (Fig. 4a).

The EMT is closely linked to stem cell properties [30, 31 , and a $117 \mathrm{kDa}$ glycoprotein containing five transmembrane domains has been suggested to be a marker of cancer stem cells (CSCs) [32, 33]. Flow cytometry was used to quantify the numbers of CD133-positive cells to assess CSC enrichment. shNOTCH2 CNE-2 cells contained significantly higher numbers of CSCs than Ctrl CNE-2 cells $(P<0.05$; Fig. 4 b) .

Next, we examined the molecular markers of EMT. Immunofluorescence staining revealed that the epithelial marker E-cadherin was downregulated and the mesenchymal marker vimentin was significantly upregulated in shNOTCH2 CNE-2 cells compared to Ctrl CNE-2 cells (Fig. 4c). Similarly, knockdown of $\mathrm{NOTCH} 2$ in CNE-2 cells induced high levels of vimentin expression and low levels of E-cadherin expression, whereas overexpression of NOTCH2 had the opposite effects $(P<0.05$; Fig. $4 d)$.

\section{NOTCH2 represses EMT in NPC cells by repressing AKT signaling}

We explored the cellular mechanisms by which $\mathrm{NOTCH} 2$ regulates EMT in NPC cells. Gene set enrichment analysis (GSEA) showed that reduced NOTCH2 expression primarily affected the mitogen-activated protein kinase (MAPK) signaling pathways $(P=0.026$; < $0.05)$ and PI3K/AKT signaling pathways $(P=0.010$; < $0.05)$ and resulted in significant alterations in biological processes and cellular components (Fig. 5a). However, Western blotting showed that several members of the MAPK family, including ERK1/2, JNK1/2 and P38, were unaffected after knockdown of NOTCH2 in CNE-2 cells $(P>0.05$; Fig. $5 b)$, indicating that MAPK signaling is not involved in the NOTCH2-mediated regulation of EMT in NPC.

At the same time, we found that knockdown of NOTCH2 increased phosphorylation of AKT, P70S6K and MTOR $(P<0.05$; Fig. $5 \mathrm{c})$. Conversely, overexpression of NOTCH2 inhibited these parameters $(P<0.05$; Fig. 5c). We used a AKT inhibitor (LY294002) to confirm whether $\mathrm{NOTCH} 2$ regulates EMT via AKT signaling. We found that the shNOTCH2 CNE-2 cells retained their cobblestone morphology when their AKT activity was inhibited, suggesting that AKT inhibitors could block the morphological changes in NOTCH2suppressed NPC cells (Fig. 5d). Cells in the shNOTCH2 + LY294002 CNE-2 group showed similar levels of migration and invasion as cells in the Ctrl CNE-2 group but showed decreased migration and invasion compared with cells in the shNOTCH2 CNE-2 group $(P<0.05)$, suggesting that AKT inhibitors block the increased migration and metastasis of $\mathrm{NOTCH} 2-$ suppressed NPC cells (Fig. 5e).

Additionally, the E-cadherin and vimentin levels in shNOTCH2 + LY294002 CNE-2 cells were not significantly different from those of Ctrl CNE-2 cells $(P>0.05)$. However, compared with Ctrl CNE-2 cells, shNOTCH2 + LY294002 CNE-2 cells had significantly upregulated E-cadherin expression levels $(P<0.05)$ and significantly downregulated vimentin expression levels $(P<0.05)$, suggesting that AKT inhibitors 

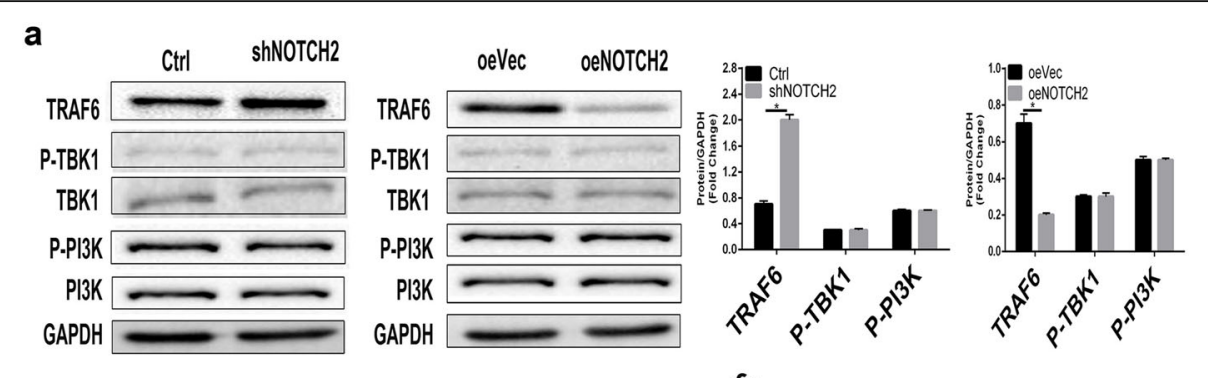

b
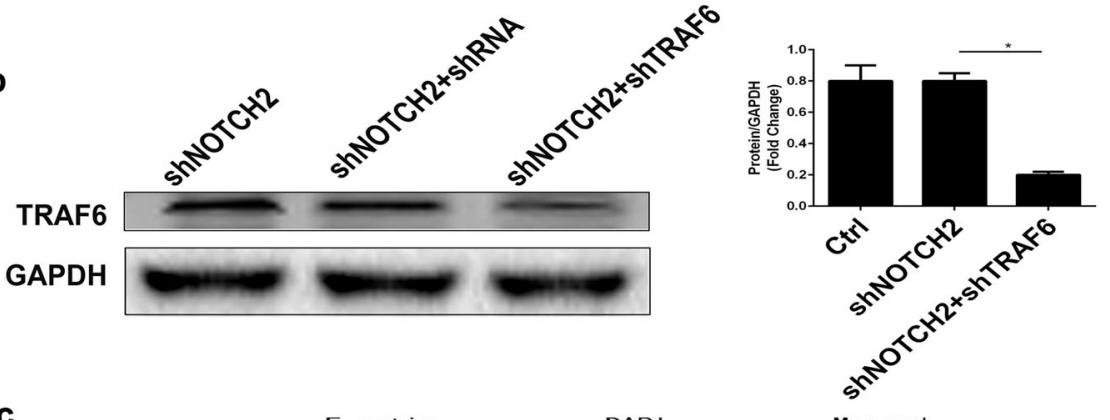

c
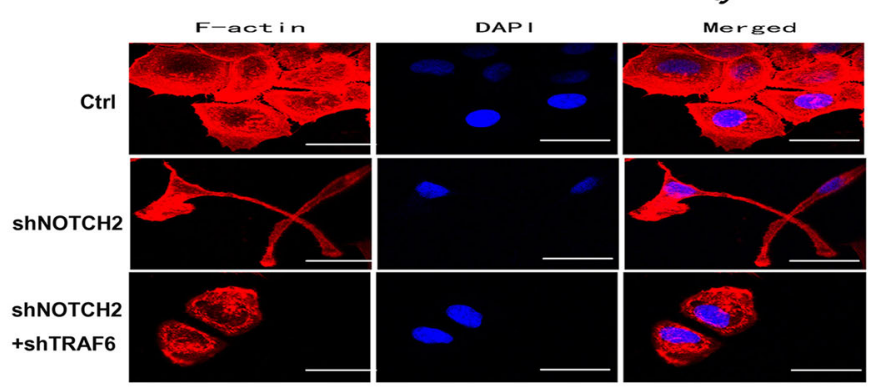

d

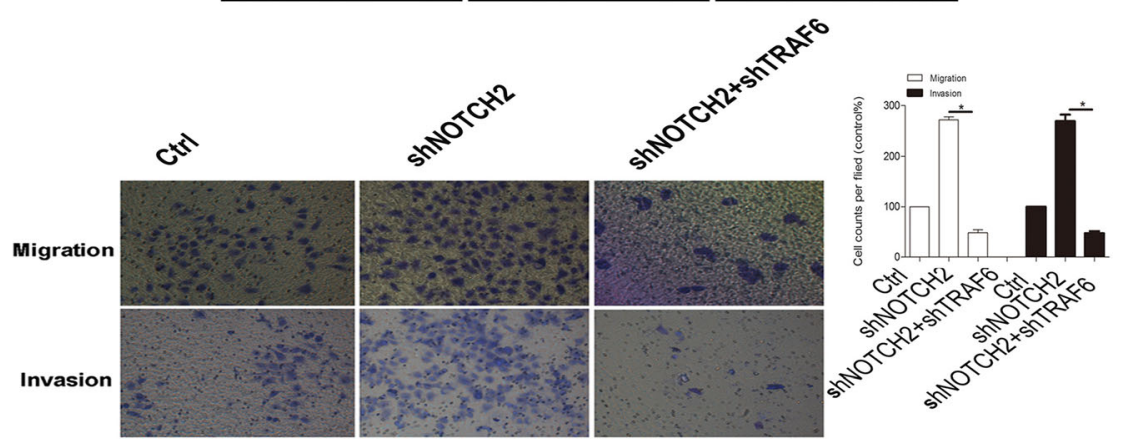

e

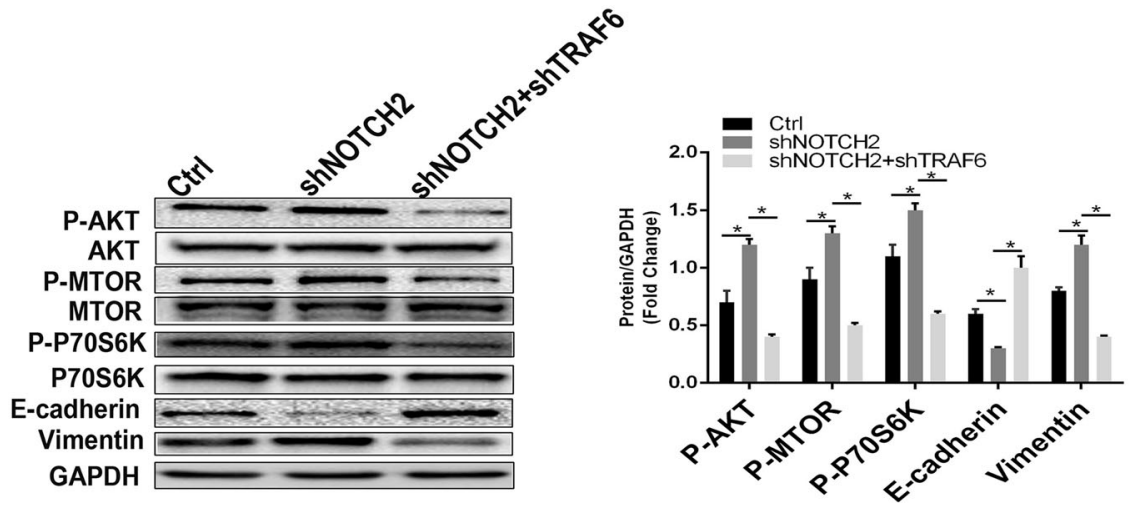

Fig. 6 (See legend on next page.) 
(See figure on previous page.)

Fig. 6 NOTCH2 negatively regulates EMT in NPC cells via the TRAF6/AKT signaling axis. a Western blots showing that knockdown of NOTCH2 activated TRAF6 and that overexpression of NOTCH2 had the opposite effects. ${ }^{*} P<0.05$, Student's $t$-test. $\mathbf{b}$ Western blots demonstrate the knockdown of TRAF6 expression. ${ }^{*} P<0.05$, one-way ANOVA. c Representative images of cytoskeletal (red) and DAPI (blue) staining in the indicated cells. $\mathbf{d}$ Transwell invasion assays showing that shTRAF6 reduced shNOTCH2 cell invasion in vitro. ${ }^{*} P<0.05$, one-way ANOVA. e Western blots showing that the knockdown of TRAF6 attenuated the activation of AKT signaling components, reduced EMT-related vimentin expression and increased E-cadherin expression in shNOTCH2 cells. ${ }^{*} P<0.05$, one-way ANOVA. Scale bars $=50 \mu \mathrm{m}$

block the EMT of NOTCH2-suppressed NPC cells (Fig. 5f).

\section{NOTCH2 prevents EMT in NPC cells by attenuating the TRAF6/AKT signaling axis}

To further investigate how $\mathrm{NOTCH} 2$ regulates EMT, we examined the effect of $\mathrm{NOTCH} 2$ on the upstream molecules of AKT, including TRAF6, TBK1 and PI3K. Overexpression of $\mathrm{NOTCH} 2$ inhibited the expression of TRAF6, whereas knockdown of NOTCH2 had the opposite effect $(P<0.05$; Fig. $6 \mathrm{a})$, indicating that $\mathrm{NOTCH} 2$ negatively regulates EMT via the TRAF6/AKT signaling axis.

To confirm that TRAF6 and AKT signaling are involved in the regulation of EMT by $\mathrm{NOTCH} 2$, we inhibited TRAF6 protein expression in shNOTCH2 CNE-2 cells using shTRAF6 $(P<0.05$; Fig. 6b) [34]. We found that shNOTCH2 + shTRAF6 CNE-2 cells had a similar morphology to Ctrl CNE-2 cells. Morphologically, the shNOTCH2 + shTRAF6 CNE-2 cells and Ctrl CNE-2 cells were cobblestone epithelial cells. The shNOTCH2 CNE-2 cells were elongated fusiform mesenchymal cells (Fig. 6c). These results suggest that the inhibition of TRAF6 can block the morphological changes in NOTCH2-suppressed NPC cells. At the same time, shNOTCH2 + shTRAF6 CNE-2 cell migration and invasion were similar to those of Ctrl CNE-2 cells but lower than those of shNOTCH2 CNE-2 cells $(P<0.05$; Fig. $6 \mathrm{~d})$. The results suggest that the inhibition of TRAF6 can block the enhanced migration and metastasis of NOTCH2-suppressed NPC cells.

Additionally, AKT, P70S6K and MTOR phosphorylation levels in the shNOTCH2 + shTRAF6 CNE-2 cells were not significantly different from those in the Ctrl CNE-2 cells. The levels in the shNOTCH2 + shTRAF6 CNE-2 cells were significantly downregulated compared with those in the shNOTCH2 cells (all, $P<0.05$; Fig. 6e). These results demonstrated that TRAF6 inhibition blocks the activation of AKT signaling in NOTCH2suppressed NPC cells. The shNOTCH2 + shTRAF6 CNE-2 cells had significantly upregulated E-cadherin levels compared with the shNOTCH2 cells $(P<0.05$; Fig. 6e). The shNOTCH2 + shTRAF6 CNE-2 cells had significantly downregulated vimentin levels compared with the shNOTCH2 cells $(P<0.05$; Fig. 6e). These results demonstrated that inhibiting TRAF6 blocks EMT in NOTCH2-suppressed NPC cells.

\section{NOTCH2 interacts with TRAF6}

The TRAF6-dependent mechanism of NOTCH2regulated EMT inspired us to investigate the molecular communications between NOTCH2 and TRAF6. Immunofluorescence staining showed complete colocalization of N2ICD and TRAF6 in the cytoplasm of the CNE2 cells (Fig. 7a). The interaction of N2ICD and TRAF6 was identified in coimmunoprecipitation (co-IP) experiments (Fig. 7b).

\section{Discussion}

Effective molecular targets must be identified to improve the treatment of NPC. NOTCH signaling is known to regulate cell proliferation and migration in NPC, indicating that this pathway may contribute to tumor progression [15]. However, inhibition of NOTCH using $\gamma$ secretase inhibitors is not sufficiently effective and is associated with many side effects [35] The individual $\mathrm{NOTCH}$ receptors exert different effects during the development of liver cancer [36]. Hayashi and colleagues recently reported that the $\mathrm{NOTCH}$ receptors had varied functions [11].

In this study, we found that low expression of $\mathrm{NOTCH} 2$ is associated with poor prognosis in human NPC. We therefore hypothesized that NOTCH2 functions as a tumor suppressor. Next, we determined that inhibition of NOTCH2 promoted NPC cell migration and invasion in vitro and promoted the formation of metastatic foci in the lung and liver in vivo. Conversely, NOTCH2 overexpression inhibited NPC cell migration and invasion in vitro and inhibited the formation of metastatic foci in the liver in vivo.

Invasion and metastasis are responsible for most deaths due to cancer [37]; distant metastasis is a major factor limiting further improvements in the treatment of NPC. EMT, a process by which epithelial cells change to a mesenchymal cell phenotype that was initially described in embryonic development [38], plays a crucial role in the regulation of invasion and metastasis [39, 40]. Knockdown of NOTCH2 induced a change from epithelial to mesenchymal morphology, reduced the expression of an epithelial marker and increased the expression of a 
a

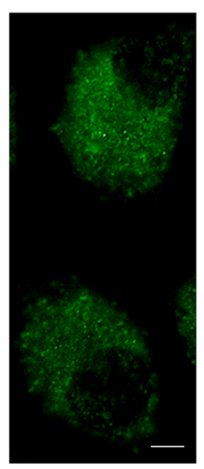

TRAF6

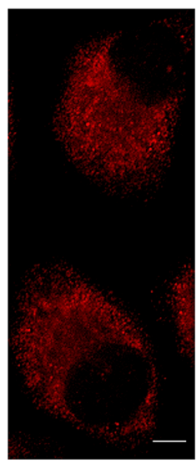

N2ICD

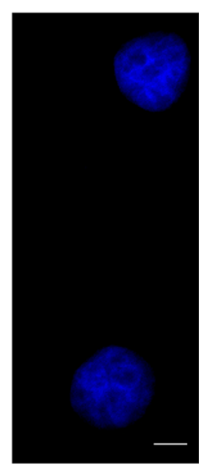

DAPI

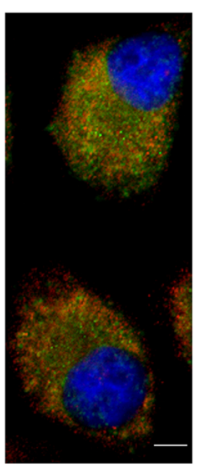

Merge

b

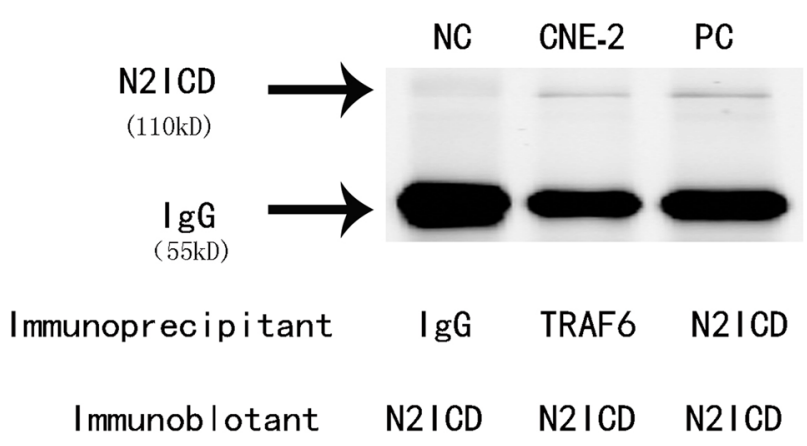

Fig. 7 NOTCH2 interacts with TRAF6. a Immunofluorescence staining demonstrated the colocalization of N2ICD and TRAF6 in CNE-2 cells. b Immunoblotting with N2ICD or TRAF6 antibody was performed on co-IP samples of N2ICD from CNE-2 cell lysates using the N2ICD antibody or TRAF6 antibody. Scale bars $=10 \mu \mathrm{m}$. (NC= negative control; $\mathrm{PC}=$ positive control)

mesenchymal marker in NPC cells, whereas NOTCH2 overexpression had the opposite effects. Therefore, our analyses suggest that $\mathrm{NOTCH} 2$ negatively regulates EMT in NPC.

Next, we investigated the signaling pathways by which $\mathrm{NOTCH} 2$ regulates EMT in NPC. Knockdown of NOTCH2 activated AKT signaling, and the inhibition of AKT blocked this effect. By screening upstream factors of AKT signaling, we found that TRAF6 is an upstream factor of AKT signaling regulated by NOTCH2. The inhibition of TRAF6 blocked the increased TRAF6-AKT signaling axis activity and EMT-related changes in NOTCH2-suppressed NPC cells.

$\mathrm{NOTCH}$ receptors contain noncovalently bound extracellular and transmembrane domains. When activated by membrane-bound delta or Jagged ligands, the receptors are proteolytically cleaved by a metalloprotease and $\gamma$-secretase to generate two fragments: the extracellular domain of NOTCH (NECD) and NICD [41, 42]. The soluble NICD is released into the cytoplasm [43]. Direct engagement of TRAF6 in AKT signaling [44, 45] can activate AKT during the growth of NPC. TRAF6 is abundantly expressed in human cancer cell lines $[20,46]$. NOTCH2 negatively regulates the ability of TRAF6-AKT to inhibit EMT and invasion and metastasis of NPC, indicating a new potential target for NPC treatment (Fig. 8). However, the specific mechanism by which N2ICD and TRAF6 binding reduces TRAF6 expression remains unclear. This issue needs to be clarified in future research.

\section{Conclusion}

$\mathrm{NOTCH} 2$ expression is low in metastatic and poorly differentiated NPC cells. NOTCH2 is associated with overall survival in NPC. NOTCH2 inhibits the invasion and metastasis of NPC cells by inhibiting EMT. NOTCH2 binds to TRAF6 and negatively regulates the EMT of NPC cells through the TRAF6-AKT signaling axis, ultimately inhibiting invasion and metastasis. Increased expression of $\mathrm{NOTCH} 2$ shows inhibitory effects similar to those of an AKT inhibitor and shTRAF6. Further investigations are warranted to explore the potential of NOTCH2 as a therapeutic target for NPC. 


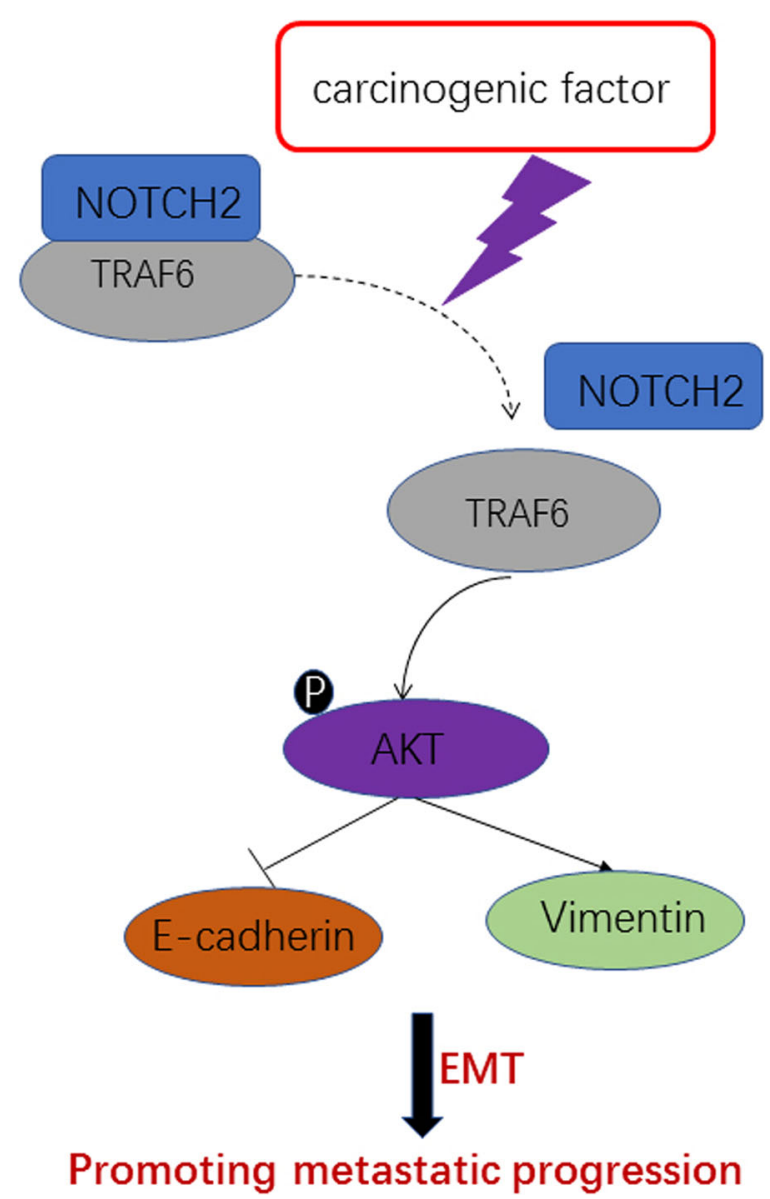

Fig. 8 Schematic diagram of the molecular mechanisms underlying NOTCH2-regulated EMT. In NPC cells, NOTCH2 interacts with TRAF6; however, NOTCH2 expression is dramatically reduced upon carcinogenic factor stimulus. TRAF6 activates the non-canonical AKT pathway. AKT activation leads to the induction of vimentin and repression of E-cadherin, which are necessary for cancer cell EMT and migration 


\section{Abbreviations}

Cl: Confidence interva; co-IP: Coimmunoprecipitation; CSCs: Cancer stem cells; DMSO: Dimethyl sulfoxide; EBV: Epstein-Barr virus; EMT: Epithelialmesenchymal transition; FBS: Fetal bovine serum; GEO: Gene expression omnibus; GSEA: Gene set enrichment analysis; GSI: Gamma-secretase inhibitor; H\&E: Hematoxylin and eosin; HR: Hazard ratio; IF: Immunofluorescence; IP: Immunoprecipitation; N2ICD: NOTCH2 intracellular domain; NECD: Extracellular domain of NOTCH; NPC: Nasopharyngeal carcinoma; OS: Overall survival; ROC: Receiver operating characteristic; TMA: Tissue microarray

\section{Acknowledgements}

Nature Research Editing Service provided professional writing services.

\section{Authors' contributions}

YZ and SC designed the experiments. YZ conducted the experiments. RY, $M H, Y K, J S, Z T, L G$ analyzed the data. YZ wrote the manuscript. All authors read and approved the final manuscript.

\section{Funding}

This work was supported by the National Natural Science Foundation of China [nos. 81172569, 81372880], the Hubei Province Health and Family Planning Scientific Research Project [nos: WJ2019M186, WJ2019M195].

\section{Availability of data and materials}

Not applicable.

\section{Ethics approval and consent to participate}

This study was reviewed and approved by the Ethical Board at Renmin Hospital of Wuhan University.

\section{Consent for publication}

Not applicable.

\section{Competing interests}

The authors declare that they have no competing interests.

\section{Author details}

'Department of Otolaryngology-Head and Neck Surgery, Renmin Hospital of Wuhan University, 238 Jie-Fang Road, Wuhan 430060, Hubei, People's Republic of China. ${ }^{2}$ Department of Endocrinology \& Metabolism, Renmin Hospital of Wuhan University, Jinan, China.

\section{Received: 26 August 2019 Accepted: 21 October 2019}

Published online: 07 November 2019

\section{References}

1. Chen YP, Chan A, Le QT, Blanchard P, Sun Y, Ma J. Nasopharyngeal carcinoma. Lancet. 2019;394(10192):64-80.

2. Lin S, Guo Q, Wen J, Li C, Lin J, Cui X, et al. Survival analyses correlate stanniocalcin 2 overexpression to poor prognosis of nasopharyngeal carcinomas. J Exp Clin Cancer Res. 2014;33:26.

3. Tang C, Wu F, Wang R, Lu H, Li G, Liu M, et al. Comparison between nedaplatin and cisplatin plus docetaxel combined with intensity-modulated radiotherapy for locoregionally advanced nasopharyngeal carcinoma: a multicenter randomized phase II clinical trial. Am J Cancer Res. 2016;6(9): 2064-75.

4. Tao Q, Chan AT. Nasopharyngeal carcinoma: molecular pathogenesis and therapeutic developments. Expert Rev Mol Med. 2007;9(12):1-24.

5. Zhang $P$, Hong $H$, Sun $X$, Jiang $H$, Ma S, Zhao S, et al. MicroRNA-10b regulates epithelial-mesenchymal transition by modulating KLF4/Notch1/Ecadherin in cisplatin-resistant nasopharyngeal carcinoma cells. Am J Cancer Res. 2016;6(2):141-56.

6. Liu B, Zhu K, Chan C, Zhang L, Mok DK, Chen S. Anticancer activities of terpenoid compounds isolated from the plant centipeda minma against nasopharyngeal carcinoma cells. Cancer Res. 2017;77(13):14.

7. Le QT, Tate D, Koong A, Gibbs IC, Chang SD, Adler JR, et al. Improved local control with stereotactic radiosurgical boost in patients with nasopharyngeal carcinoma. Int J Radiat Oncol Biol Phys. 2003;56(4):1046-54.
8. Yip KW, Mocanu JD, Au PY, Sleep GT, Huang D, Busson P, et al. Combination bcl-2 antisense and radiation therapy for nasopharyngeal cancer. Clin Cancer Res. 2005;11(22):8131-44.

9. Al Tamimi AS, Zaheer S, Ng DC, Osmany S. 18F-Fluorodeoxyglucosepositron emission tomography/computed tomography imaging of metastatic nasopharyngeal Cancer with emphasis on the distribution of bone metastases. World J Nuclear Med. 2017;16(3):192-6.

10. Egloff AM, Grandis JR. Molecular pathways: context-dependent approaches to notch targeting as cancer therapy. Clin Cancer Res. 2012;18(19):5188-95.

11. Hayashi T, Gust KM, Wyatt AW, Goriki A, Jager W, Awrey S, et al. Not all NOTCH is created equal: the oncogenic role of NOTCH2 in bladder Cancer and its implications for targeted therapy. Clin Cancer Res. 2016;22(12):2981-92.

12. Hibdon ES, Razumilava N, Keeley TM, Wong G, Solanki S, Shah YM, et al. Notch and mTOR signaling pathways promote human gastric Cancer cell proliferation. Neoplasia. 2019;21(7):702-12.

13. Augert A, Eastwood E, Ibrahim AH, Wu N, Grunblatt E, Basom R, et al. Targeting NOTCH activation in small cell lung cancer through LSD1 inhibition. Sci Signal. 2019;12(567):1-15.

14. Backer RA, Hombrink P, Helbig C, Amsen D. The fate choice between effector and memory T cell lineages: asymmetry, signal integration, and feedback to create Bistability. Adv Immunol. 2018;137:43-82.

15. Chen SM, Liu JP, Zhou JX, Chen C, Deng YQ, Wang Y, et al. Suppression of the notch signaling pathway by gamma-secretase inhibitor GSI inhibits human nasopharyngeal carcinoma cell proliferation. Cancer Lett. 2011; 306(1):76-84.

16. Williams R. Discontinued drugs in 2012: oncology drugs. Expert Opin Investig Drugs. 2013;22(12):1627-44.

17. Liao SY, Kuo IY, Chen YT, Liao PC, Liu YF, Wu HY, et al. AKT-mediated phosphorylation enhances protein stability and transcription activity of ZNF322A to promote lung cancer progression. Oncogene. 2019; 38(41): 6723-36.

18. Shin SH, Lee GY, Lee M, Kang J, Shin HW, Chun YS, et al. Aberrant expression of CITED2 promotes prostate cancer metastasis by activating the nucleolin-AKT pathway. Nat Commun. 2018;9(1):4113-27.

19. Rezaeian AH, Li CF, Wu CY, Zhang X, Delacerda J, You MJ, et al. A hypoxiaresponsive TRAF6-ATM-H2AX signalling axis promotes HIF1alpha activation, tumorigenesis and metastasis. Nat Cell Biol. 2017;19(1):38-51.

20. Chen L, Li YC, Wu L, Yu GT, Zhang WF, Huang CF, et al. TRAF6 regulates tumour metastasis through EMT and CSC phenotypes in head and neck squamous cell carcinoma. J Cell Mol Med. 2018;22(2):1337-49.

21. David JM, Hamilton DH, Palena C. MUC1 upregulation promotes immune resistance in tumor cells undergoing brachyury-mediated epithelialmesenchymal transition. Oncoimmunology. 2016;5(4):e1117738.

22. Zheng XK, Chen LH, Wang WJ, Ye F, Liu JB, Li QS, et al. Impact of prolonged fraction delivery times simulating IMRT on cultured nasopharyngeal carcinoma cell killing. Int J Radiat Oncol Biol Phys. 2010;78(5):1541-7.

23. Han P, Chen RH, Wang F, Zeng JY, Yu ST, Xu LH, et al. Novel chimeric transcript RRM2-c2orf48 promotes metastasis in nasopharyngeal carcinoma. Cell Death Dis. 2017;8(9):e3047.

24. Liu N, Jiang N, Guo R, Jiang W, He QM, Xu YF, et al. MiR-451 inhibits cell growth and invasion by targeting MIF and is associated with survival in nasopharyngeal carcinoma. Mol Cancer. 2013;12(1):123.

25. Chen HY, Islam A, Yuan TM, Chen SW, Liu PF, Chueh PJ. Regulation of tNOX expression through the ROS-p53-POU3F2 axis contributes to cellular responses against oxaliplatin in human colon cancer cells. J Exp Clin Cancer Res. 2018;37(1):161.

26. Vizza E, Corrado G, De Angeli M, Carosi M, Mancini E, Baiocco E, et al. Serum DNA integrity index as a potential molecular biomarker in endometrial cancer. J Exp Clin Cancer Res. 2018;37(1):16.

27. Dodd LE, Sengupta S, Chen IH, den Boon JA, Cheng YJ, Westra W, et al. Genes involved in DNA repair and nitrosamine metabolism and those located on chromosome $14 q 32$ are dysregulated in nasopharyngeal carcinoma. Cancer Epidemiol Biomark Prev. 2006;15(11): 2216-25.

28. Bose S, Yap LF, Fung M, Starzcynski J, Saleh A, Morgan S, et al. The ATM tumour suppressor gene is down-regulated in EBV-associated nasopharyngeal carcinoma. J Pathol. 2009;217(3):345-52.

29. Tang XR, Wen X, He QM, Li YQ, Ren XY, Yang XJ, et al. MicroRNA-101 inhibits invasion and angiogenesis through targeting ITGA3 and its systemic delivery inhibits lung metastasis in nasopharyngeal carcinoma. Cell Death Dis. 2017;8(1):e2566. 
30. Liang Z, Lu L, Mao J, Li X, Qian H, Xu W. Curcumin reversed chronic tobacco smoke exposure induced urocystic EMT and acquisition of cancer stem cells properties via Wnt/beta-catenin. Cell Death Dis. 2017;8(10):e3066.

31. Kaufhold S, Bonavida B. Central role of Snail1 in the regulation of EMT and resistance in cancer: a target for therapeutic intervention. J Exp Clin Cancer Res. 2014;33:62.

32. Argaw-Denboba A, Balestrieri E, Serafino A, Cipriani C, Bucci I, Sorrentino R, et al. HERV-K activation is strictly required to sustain CD133+ melanoma cells with stemness features. J Exp Clin Cancer Res. 2017;36(1):20.

33. Joseph C, Arshad M, Kurozomi S, Althobiti M, Miligy IM, Al-Izzi S, et al. Overexpression of the cancer stem cell marker CD133 confers a poor prognosis in invasive breast cancer. Breast Cancer Res Treat. 2019;174(2): 387-99.

34. Qiu GZ, Mao XY, Ma Y, Gao XC, Wang Z, Jin MZ, et al. Ubiquitin-specific protease 22 acts as an oncoprotein to maintain glioma malignancy through deubiquitinating B cell-specific Moloney murine leukemia virus integration site 1 for stabilization. Cancer Sci. 2018;109(7):2199-210.

35. Wang Z, Hu Y, Xiao D, Wang J, Liu C, Xu Y, et al. Stabilization of Notch1 by the Hsp90 chaperone is crucial for T-cell Leukemogenesis. Clin Cancer Res. 2017;23(14):3834-46

36. Huntzicker EG, Hotzel K, Choy L, Che L, Ross J, Pau G, et al. Differential effects of targeting notch receptors in a mouse model of liver cancer. Hepatology. 2015;61(3):942-52.

37. Oh E, Kim YJ, An H, Sung D, Cho TM, Farrand L, et al. Flubendazole elicits anti-metastatic effects in triple-negative breast cancer via STAT3 inhibition. Int J Cancer. 2018:143(8):1978-93.

38. Neumann DP, Goodall GJ, Gregory PA. Regulation of splicing and circularisation of RNA in epithelial mesenchymal plasticity. Semin Cell Dev Biol. 2018;75:50-60.

39. Xiao S, Chang RM, Yang MY, Lei X, Liu X, Gao WB, et al. Actin-like 6A predicts poor prognosis of hepatocellular carcinoma and promotes metastasis and epithelial-mesenchymal transition. Hepatology. 2016;63(4): 1256-71.

40. Valastyan S, Weinberg RA. Tumor metastasis: molecular insights and evolving paradigms. Cell. 2011;147(2):275-92.

41. Kopan R, llagan MX. The canonical notch signaling pathway: unfolding the activation mechanism. Cell. 2009;137(2):216-33.

42. Wang K, Zhang Q, Li D, Ching K, Zhang C, Zheng X, et al. Identification of drug-sensitive Notch receptor alterations in human breast cancer. Cancer Res. 2015;75(22):52

43. Naveed M, Imran K, Mushtaq A, Mumtaz AS, Janjua HA, Khalid N. In silico functional and tumor suppressor role of hypothetical protein PCNXL2 with regulation of the notch signaling pathway. RSC Adv. 2018;8(38):21414-30.

44. Wang $Y$, Zhou $C$, Huo J, Ni Y, Zhang P, Lu C, et al. TRAF6 is required for the GM-CSF-induced JNK, p38 and Akt activation. Mol Immunol. 2015;65(2):224-9.

45. Zhang L, Wang Y, Xiao F, Wang S, Xing G, Li Y, et al. CKIP-1 regulates macrophage proliferation by inhibiting TRAF6-mediated Akt activation. Cell Res. 2014;24(6):742-61

46. Min SK, Jung SY, Kang HK, Park SA, Lee JH, Kim MJ, et al. Functional diversity of miR-146a-5p and TRAF6 in normal and oral cancer cells. Int J Oncol. 2017;51(5):1541-52.

\section{Publisher's Note}

Springer Nature remains neutral with regard to jurisdictional claims in published maps and institutional affiliations.

Ready to submit your research? Choose BMC and benefit from:

- fast, convenient online submission

- thorough peer review by experienced researchers in your field

- rapid publication on acceptance

- support for research data, including large and complex data types

- gold Open Access which fosters wider collaboration and increased citations

- maximum visibility for your research: over $100 \mathrm{M}$ website views per year

At BMC, research is always in progress.

Learn more biomedcentral.com/submissions 